\section{EL FINAL DE UNA TENSIÓN ESENCIAL: ANALÍTICOS Y CONTINENTALES. HERMENÉUTICA FILOSÓFICA Y TEORÍAS DE LA ARGUMENTACIÓN}

\author{
María G. Navarro \\ Department of Speech Communication, \\ Argumentation Theory and Rhetoric \\ Faculty of Humanities. University of Amsterdam/ \\ Instituto de Filosofía. Centro de CC. Humanas y Sociales \\ Consejo Superior de Investigaciones Científicas
}

\begin{abstract}
The author presents the hypothesis that the foundations of the so-called speculative theories of argumentation are to be found in philosophical hermeneutics. To demonstrate the strength of this hypothesis the author explores the most famous historical thesis regarding the connection between analytical and continental thought. In addition, she also presents an analysis of concepts (plausibility, dialectic, rhetoric, heuristic reasoning, and reasoning topic) to show the hermeneutical basis of developments in the field of argumentation theories.
\end{abstract}

KEY WORDS: Hermeneutics; argumentation theories; topic; heuristics; plausibility; analytical philosophy; continental philosophy.

\section{Plausibilidad y dialéctica}

Las definiciones de argumentación son tan variadas como las distintas posiciones existentes en torno a la pregunta de qué hacemos exactamente cuando argumentamos y cuándo estamos, de hecho, argumentando. Incluso el mismo autor puede ofrecer más de una definición de lo que entiende por argumentación; en parte, porque el problema de la argumentación no se circunscribe a un solo ámbito, ni del conocimiento, ni de la vida práctica.

Sea como fuere, y para todos los casos, llama nuestra atención que no se haya analizado el problema de la argumentación (sobre todo en su aplicación a métodos hipotético-inductivos) como un problema colindante con el de la interpretación. Que la argumentación colinda con la interpretación y viceversa se ve claramente por dos
THE END OF AN ESSENTIAL TENSION: ANALITICS AND CONTINENTALS. PHILOSOPHICAL HERMENEUTICS AND ARGUMENTATION THEORIES

RESUMEN: La autora presenta la hipótesis de que es en la hermenéutica filosófica donde se encuentran los fundamentos especulativos de las llamadas teorias de la argumentación. Para mostrar la consistencia de esta hipótesis no sólo se exploran las más famosas tesis históricas sobre la conexión entre analíticos y continentales, sino que se presenta un análisis de conceptos (plausibilidad, dialéctica, retórica, razonamiento heurístico, razonamiento tópico) del que se desprenden las bases hermenéuticas de los desarrollos en el campo de las teorias de la argumentación.

PALABRAS CLAVE: Hermenéutica; teorias de la argumentación; tópica; heurística; plausibilidad; filosofía analítica; filosofía continental.

razones: la primera, porque si "la argumentación es una de las características de la vida racional" (Corcoran 1994, pp. 27-55), se debe a que la radical necesidad de interpretar el medio político y social, histórico, institucional, personal, etc., en el que se desarrolla nuestra existencia (y no sólo la nuestra, anclada en el presente, sino la pasada, así como la futura), hace de la argumentación un medio más para dirigir esa sustantiva y elemental disposición de la existencia humana que lleva a hacer uso de la interpretación como un medio y un fin. La segunda razón estriba en que, desde un punto de vista lógico, la aplicación de la argumentación a los métodos hipotético-deductivos e hipotético-inductivos va de suyo, en la medida en que ambos métodos parten de procedimientos conjeturales. Podemos distinguir esta segunda razón, de naturaleza lógica, de la primera, que aludiría a las dimensiones ontológicas e históricas. 
Una definición de argumentación en la que se aúnan ambas dimensiones (la estrictamente lógica y la ontológica) es esta que sigue: "La argumentación está involucrada en la reducción de problemas nuevos a otros viejos que han sido resueltos" (Corcoran, 1994, p. 29). Sin embargo, un argumento con el que mostrar que ni el método deductivo ni el inductivo son propiamente métodos encaminados al descubrimiento de hipótesis se obtiene cuando se observa que "[...] ninguno de estos métodos es un método para descubrir cadenas de razonamientos" (Corcoran, ibidem, p. 30). Luego existirian procedimientos coadyutorios para descubrir hipótesis que además servirian para hallar posibles cadenas de razonamientos. Estas vías de descubrimiento 0 hallazgo de hipótesis son propiamente vías heuristicas, es decir, son parte de un ars inveniendi que hunde sus raices en un ars interpretandi, y que se contrapone al ars iudicandi, pues no sigue una lógica demostrativa como éste último. Así, por ejemplo, el método por analogía es un procedimiento heurístico.

La aplicación de procedimientos interpretativos o conjeturales puede conducir a la producción y aportación de pruebas cuando, por ejemplo, se hace uso de un procedimiento heurístico consistente en desarrollar, a partir de una hipótesis originaria, argumentos que van comprobándose verdaderos. Así es como, a partir de interpretaciones y conjeturas que se apoyan sobre petitio principii, se pueden convertir a éstos en pruebas. Todo ello habría de dar idea de las potencialidades epistémicas de los procesos interpretativos en su dimensión heuristica.

Según Stuart Russell y Peter Norvig, la función heuristica suele estimar "el costo de una solución que comienza desde el estado en el nodo $n^{\prime \prime \prime}$ (Russell y Norvig, 2004, p. 773) y que, a todas luces, consigue construir una función aprendiendo de la experiencia, ya que cada solución óptima en un problema cualquiera proporciona elementos o ejemplos para que se pueda aprender la función $h(n)$. Esto es, que cada ejemplo se compone de un estado del camino solucionado; de manera que es por este motivo por el que suele decirse que una estrategia heurística -se aplique o no ulteriormente a un razonamiento- utiliza el conocimiento de un problema en un sentido que va más allá de la definición del problema en sí mismo. Esta estrategia pone en juego una modalidad de aprendizaje y de razonamiento que no es deductivo sino inductivo.
El aprendizaje inductivo sólo se puede desplegar si se le ofrece al sistema que haya de realizar dicho cálculo una información que, por las razones que fuera, sea relevante para la evolución y descripción del problema. Muchas veces, $\sin$ embargo, haciendo uso de este mismo esquema procedimental, se echa en falta que las conclusiones obtenidas se sigan efectivamente de la argumentación. Y también suele suceder que cuando no se hace con rigor generalmente se le achaca al procedimiento interpretativo de naturaleza heuristica, exploratoria, una limitación lógica que no depende propiamente de él, sino del procedimiento lógico-discursivo mediante el cual conducimos los argumentos. Cuando dicho procedimiento no se realiza con rigor, invalidamos un procedimiento heuristico transformándolo en una mera falacia o conclusión equivocada a consecuencia bien de un encadenamiento equívoco, bien de basar la fuerza de los razonamientos en una interpretación errada acerca del sentido implícito en esa petición de principio.

La estrategia heuristica - profundamente hermenéuticapone en juego una modalidad de razonamiento inductivo. Como puede observarse, el razonamiento y el aprendizaje inductivos sólo se pueden desplegar si se le ofrece al sistema que haya de realizar dicho cálculo una información que, por las razones que fuera, sea relevante para la evolución y descripción del problema.

Todos estos factores parecen poner en tela de juicio la idoneidad del esquema lineal basado en el razonamiento y aprendizaje mecánicos e incluso en concepciones del lenguaje como mero instrumento para la representación del conocimiento. Estas concepciones del razonamiento heurístico y hermenéutico se ponen de manifiesto, por ejemplo, en el diseño de ambientes inteligentes para los que es menester investigar los procesos cognitivos implicados en el razonamiento: un campo de plena actualidad en Inteligencia Artificial. En dicho ámbito, los agentes lógicos ya no se diseñan teniendo a la vista lenguajes de programación según patrones de razonamiento prototípicos de la lógica proposicional (por ejemplo, siguiendo el desarrollo de patrones de inferencia que se puedan aplicar para derivar cadenas de conclusiones que nos llevarian a un objetivo deseado). Por el contrario, hoy en día, se tienen a la vista modelos más complejos como, por ejemplo, los consistentes en la descripción de acciones para realizar cálculos e interpretaciones de situaciones en las cuales 
suele darse un axioma de posibilidad (que da una idea de cuándo es posible o necesario realizar una acción determinada) y un axioma de efecto (que da una idea de qué sucede cuando se ejecuta una acción o qué cambios son posibles como resultado de realizar un acción).

Pese a estas conexiones entre razonamiento heurístico y hermenéutica, en la historia de la hermenéutica, especialmente en la etapa romántica, se asociaba a aquélla con el problema de simples malos entendidos (una forma algo roma de expresar la problemática a la que nos hemos referido arriba). Igualmente se ha insistido en que la función de la hermenéutica (claramente epistémica, a juicio mío) era, sencillamente, la de una propedéutica para alcanzar una correcta interpretación o comprensión en los casos en los que se nos manifiesta algo confuso, obtuso, ininteligible o mal entendido, cuando por lo general es el caso que ese algo se habría de presentar inteligible, claro y perceptible.

Sin embargo, el hecho de mantener que los procedimientos heurísticos - de una u otra manera siempre de naturaleza interpretativa- colindan con los argumentativos debilita la idea de que existan acaso argumentos que den lugar a razonamientos cogentes per se. Normalmente se considera que un razonamiento es cogente per se si la conclusión que ofrece se sigue lógicamente de las premisas de que ha dispuesto. No obstante, con demasiada frecuencia observamos que esta circunstancia se puede dar de modo tal que las personas no reconozcan la consistencia de la conclusión exhibida bien porque no acepten las premisas utilizadas, bien porque sencillamente las desconozcan. Eso habría de dar idea de hasta qué punto confluyen en la práctica los procesos interpretativos y los estrictamente lógicos. Por tanto, que pese a la pulcritud lógica en la cadena de razonamiento, una argumentación puede no ser una prueba para una persona o un conjunto de personas en un contexto particular $y$, en ese caso, ser simplemente peticiones de principio.

Frecuentemente, este fenómeno (de naturaleza lógica, y en el que entrarian en juego los elementos pragmáticos ínsitos en el razonamiento) se confunde con un problema relativo al empleo de interpretaciones equívocas. Es decir, se confunde una petición de principio con una mera interpretación sin valor epistémico ni lógico. Este fenómeno tan frecuente en la comunicación de la vida en común está fundado en una razón: una argumentación correcta no es meramente el resultado de un proceso inferencial, de manera que tampoco una interpretación adecuada o coherente se presenta siempre bajo la forma de una argumentación cogente.

Que las expectativas de llevar a buen término nuestras interpretaciones son de tipo lógico se aprecia en lo molesto que puede llegar a resultar que nuestro interlocutor formule interpretaciones manifiesta o claramente erradas a partir de acontecimientos, textos, relatos, etc. que habrían de llevar a otras interpretaciones. Acostumbramos a vincular los procesos interpretativos con los lógicos o, al menos, con ciertas dimensiones de la lógica que, si bien asumimos desde cierta flexibilidad en la conversación relajada 0 , en general, en la vida en común, no podríamos dejar tampoco por ello de exigir o presuponer en todo acto de habla.

Mas también cabe advertir que el hecho de que descalifiquemos a nuestro interlocutor diciendo: "jesa es tan sólo tu interpretación!", no hace sino abundar en lo anteriormente dicho, es decir, la razón de ser de esta descalificación o recriminación radica en que se hace depender de la subjetividad del interlocutor la dilucidación de una cuestión que habría de conducir a alguna forma de comunión en el razonamiento. Cuando es así, se habla de interpretaciones erradas, es decir, interpretaciones que no cumplen adecuadamente su función heurística y que, por ello, resultan tan ilógicas como personales o subjetivas.

Sostenemos en fin que una de las claves argumentativas en lo que concierne a la conexión entre interpretación y argumentación radica en que tanto la existencia de premisas como de conclusión(es) tiene un carácter meramente funcional en los procesos argumentativos, y ello en virtud precisamente de que las argumentaciones tienen un alcance interpretativo: a partir de ellas se inducen otras proposiciones, conclusiones o interpretaciones, por lo que todas son temporales.

Corcoran se ha referido a este problema aduciendo que es particularmente llamativo que muchos filósofos escépticos o incluso nihilistas epistemológicos hayan concluido que ninguna proposición se sabe verdadera en sí misma. Sin embargo, pocos han hecho ver a partir de esta sentencia que realmente ello indica que ningún razonamiento se sabe válido si pensamos que para constatar como válido un 
argumento es preciso tener por válidos otros argumentos, por lo que siempre habría algún argumento que se daria como válido por necesidad, a fin de dar por válidos al resto. Todo argumento es un argumento concreto y singular: no hay un esquema o un a priori de la argumentación, esto implica que todo proceso inductivo está basado en argumentos concretos y que consiguientemente le asisten procedimientos heurísticos de tipo hermenéutico. Si esto es así, parece razonable ampliar el dominio de investigación de la disciplina de la lógica con el problema propiamente hermenéutico.

A partir de lo expuesto puede tenerse por consistente y completa que la anterior esta otra definición de argumentación, en la que se incorporan todos los problemas hasta aquí referidos: "Una argumentación es un sistema de tres partes compuesto de un conjunto de proposiciones llamado el conjunto de premisas, una única proposición llamada la conclusión y un discurso llamado la cadena de razonamiento" (Corcoran, 1994, p. 36).

En la elaboración de argumentos obtenidos tanto a través de un método hipotético-inductivo como hipotético-deductivo intervienen premisas que se dan como válidas o bien otros argumentos cuya validez se da por demostrada. Por lo general, son estos los argumentos y las proposiciones plausibles que Aristóteles consideraba dignas de consideración o de crédito en la medida en que gozaban de reputación. Son las éndoxa definidas como "proposiciones dialécticas más 0 menos aceptadas o aceptables" (Vega, 1993, p. 6).

Según sostiene Vega, las éndoxa generan su propio modelo de argumentación. Aristóteles ya les confirió el espacio propio del silogismo dialéctico. Aquí adoptamos el punto de vista de Vega, según el cual las éndoxa tienen dos rasgos primordiales: por una parte, su condición pragmática $y$, de la otra, su gradualismo. En efecto, nos parece claro por todo lo expuesto que la plausibilidad de un argumento se basa en elementos pragmáticos, y no en aspectos semánticos -relativos al significado específico de cada argumento ora atendiendo a sus premisas, ora a sus conclusiones. Ahora bien, también hemos hecho aquí hincapié en que hay argumentos que, aunque concluyan adecuadamente, podrían no llegar a gozar de plausibilidad. Esto es así porque lo plausible no es resultado de una cadena de argumentos lógicamente consistente sino del criterio con el cual se lleva a efecto un juicio: ya que la argumentación puede tratar asuntos que se presten a una elaboración dialéctica. Este es el punto de vista del que parte Gadamer, a saber: que las cuestiones filosóficas sólo se pueden considerar desde la perspectiva dialéctica por eso el método más adecuado para ellas es el diálogo.

Como se habrá de ver más adelante, no podría aplicarse una teoría de la argumentación en sentido filosófico que hubiera de abordar problemas políticos, epistemológicos, ontológicos, éticos, etc. que no estuviera plenamente integrada en una tópica. Es a partir de esta circunstancia como se observa la estrecha conexión entre los procesos argumentativos y los interpretativos pues, por decirlo con toda simplicidad, el procedimiento interpretativo comienza alli donde no cabe aplicar deductivamente el razonamiento: alli donde la plausibilidad sólo puede medirse según un cierto grado. Vega $(1993$, p. 14) ha expresado este problema en los siguientes términos:

En otras palabras: para que un argumento $<\left\{\alpha_{1}, \alpha_{2}, \ldots \alpha_{k}\right\}$, $\alpha_{n}>$ sea efectivamente una prueba, es necesario que su poder de aceptación o su plausibilidad sea mayor que la de la mera proposición de $\alpha_{n}$ en el marco discursivo dado.

Cuándo un argumento resulta plausible o no es un problema dependiente de marcos discursivos, esto es, de contextos pragmáticos e históricos cuya significación puede ser definida como el producto final pero temporáneo de la compleja lógica de las interpretaciones. Schnädelbach (2000, p. 409) ha expresado en estos términos la tesis que aquí buscamos pergeñar:

Si la racionalidad discursiva es esencialmente un asunto de la facultad de juzgar [...] el contexto de la crítica y la justificación nunca puede ser acotado completamente por reglas, aún cuando debe seguir [...] ciertas reglas elementales (por ejemplo, las de la gramaticalidad o la consistencia lógica). Por consiguiente, una lógica de la argumentación nunca será posible como teoría puramente axiomático-deductiva [...].

\section{Algunas perspectivas en el abordaje DEL PROBLEMA DE LA ARGUMENTACIÓN}

Existen tres elementos centrales para abordar el problema de la argumentación: el pragmático, el hermenéutico y el 
propiamente argumental. Asimismo, el análisis del problema de la argumentación conduce a importantes temas filosóficos relacionados, a su vez, con el debate en torno al sentido, el alcance y los límites de la racionalidad o la dimensión heurística e interpretativa del razonamiento. Por ejemplo, hemos hecho alusión a la distinción entre la persuasión y la convicción, temas que establecerían el vínculo entre la intencionalidad presente en la dimensión argumentativa de los intercambios comunicativos y la retórica. Mas también puede hacerse alusión a la dimensión dialógica y a las reglas dialécticas que presiden en los intercambios comunicativos polémicos.

\section{R. Marafioti, B. Zamudio y A. Rubione (1997) consideran} que algunos de los enfoques más destacados acerca del problema de la argumentación no han dado cuenta suficientemente de aspectos tales como la influencia que las instituciones sociales ejercen sobre los discursos argumentativos, indicando con ello que sería menester contar con una sociología de la argumentación. Igualmente importante es que la construcción de teorias en torno a la argumentación observe que ésta aconseja el estudio de la argumentación desde una perspectiva psicolingüística en la que fueran objeto de investigación problemas como la psicogénesis de la competencia argumentativa, así como los presupuestos contextuales compartidos para realizar inferencias. Marafioti destaca además otro punto de vista en el estudio de la argumentación como es el de la teoría de la enunciación que ha conseguido ampliar ostensiblemente la definición de argumento que en la retórica tradicional se ajustó a un cierto esquema (exordio, narratio, confirmatio, etc.) incrementado, a día de hoy, por otras formas de discursividad generadoras de dimensiones argumentativas En definitiva, los aspectos retóricos, dialécticos y lógicos habrían de enriquecerse con perspectivas tales como la sociología de la argumentación, la psicología de la argumentación y los estudios en lingüística en torno a las estrategias de enunciación y demarcación de las múltiples estructuras de un texto, y su influencia sobre una visión más compleja de los procedimientos y procesos argumentativos.

Sin embargo, tampoco hay que olvidar que esta perspectiva estaba ya presente en el pensamiento aristotélico pues, si bien la dialéctica se ocupa del problema de la demostración cuando las premisas no son verdaderas sino probables y la retórica comprende el estudio de las técnicas o proce- dimientos adecuados para conseguir efectos persuasivos, ambas, dialéctica y retórica, no pertenecen a una ciencia determinada, sino que se sustentan en cuestiones y aspectos que todas las personas conocen por algún medio por el hecho de formar parte de una comunidad política y tener competencias comunicativas. Si nos fijamos, estos presupuestos aristotélicos están presentes tanto en la investigación de J.-B. Grize como en la investigación de J. Habermas. Desde un punto de vista semántico, la primera de ellas se ocupa de la reconstrucción de los esquemas que hacen posible la articulación e interpretación de un discurso, ampliando con ello el concepto de lógica aplicado al campo de la argumentación. Mientras que en la investigación del segundo se sostiene un planteamiento equivalente al de Grize en este punto, si hacemos la salvedad de que, a juicio del filósofo alemán, serían los aspectos pragmáticos, y no las oraciones tomadas como unidades semánticas, las causas principales de la producción de una lógica informal de la argumentación.

Todo parece indicar que el estudio de la argumentación constituye un campo que va más allá de los límites de una lógica formal deductiva e inductiva, encaminándose, según mi punto de vista, hacia el universo de problemas propio de la hermenéutica.

Las definiciones de argumentación presentadas en el parágrafo anterior se han visto completadas en la historia de las teorías de la argumentación con enfoques como el de Anscombre y Ducrot para quienes la argumentación es un acto comunicativo en el que se presenta un enunciado con la finalidad de apoyar una conclusión, pudiendo contribuir a su fuerza argumentativa la aplicación de otros enunciados elegidos con objeto de apoyar la misma conclusión u otra que, presentándose más obvia en un contexto determinado, pudiera reforzar o incluso presentarse como una prueba de la conclusión a debatir. Victoria Escandell lo ha sabido expresar al apuntar al hecho de que con respecto al problema de la argumentación, a diferencia de la tradición pragmática inglesa más interesada "en poner de relieve el carácter de acción que subyace a toda comunicación lingüística" (Escandel, 1999, p. 109), la tradición francesa (entre quienes figuran Anscombre y Ducrot) ha prestado mayor atención a los principios que determinan los efectos argumentativos de los enunciados que al contexto lingüístico en que éstos se inscriben, dándose el caso de que en la práctica comunicativa los enunciados que cabe 
caracterizar como argumentos se alejan de las leyes lógicas discursivas clásicas.

Todo ello da cuenta de la existencia de operadores ${ }^{1}$ y conectores $^{2}$ argumentativos tan sutiles o complejos como para estar presentes en textos que, en principio, no tienen una función argumentativa sino incluso poética, narrativa, descriptiva, etc. $Y$ eso sin contar con la perspectiva habermasiana en torno a los actos de habla como desencadenantes de las unidades pragmáticas que en contextos sociales y políticos determinados vivifican la potencia argumentativa de los textos con independencia del contenido semántico primigeniamente establecido con objeto de alcanzar determinadas pretensiones de validez. Todo ello refuerza, si no me equivoco, el punto de vista de Ducrot en torno a la preeminencia de la función argumentativa de la lengua sobre el resto de las funciones, en la medida en que ésta subyace bajo todas las demás.

Los trabajos de Anscombre y Ducrot son relevantes para esta investigación sobre todo en lo que respecta a un punto, a saber, si bien los enunciados se pueden orientar argumentativamente mediante procedimientos formales (por lo que su apuesta sería la de una semántica compleja, que abarcaría a la pragmática), la interpretación de los mismos parece depender de medios formales específicos. De manera que, en los procesos comunicativos, la interpretación representaría la otra cara o el reverso de la argumentación, y podría explicarse como el proceso cognitivo mediante el cual el receptor distingue los conectores y los operadores argumentativos Ilegando así a establecer un valor final en la ecuación de sentido. Sin embargo, esta definición resulta aún excesivamente semántica ya que lo cierto es que en la mayoría de las ocasiones comprobamos que tanto los argumentos como las conclusiones están implícitas, por lo que la tarea consiste mayormente en saber interpretar la orientación argumentativa de un discurso, en términos pragmáticos y semánticos, más que en distinguir sus operadores y conectores en términos formales.

El corolario que podría extraerse acerca de la hipótesis de investigación planteada por los autores es que los procesos interpretativos actualizan otras dimensiones del razonamiento discursivo como son un discernimiento comprensivo de la situación, una valoración adecuada de los topoi empleados explícita y/o implícitamente, así como de las técnicas retóricas y los límites dialécticos utilizados para orientar el discurso o el enunciado argumentativamente a fin de ora mostrar la probabilidad de una argumentación en particular, ora contra-argumentarla. El punto de vista de Anscombre y Ducrot $(1994$, p. 8) queda singularmente recogido en este fragmento:

Nuestra tesis es que en la lengua hay restricciones que determinan esta presentación. Para que un enunciado $E_{1}$ pueda darse como un argumento a favor de $E_{2}$ (conclusión) no basta con que efectivamente $E_{1}$ dé razones para aceptar $E_{2}$. La estructura lingüistica de $E_{1}$, debe, además, satisfacer ciertas condiciones que la hagan apta para constituir, en un discurso, un argumento para $E_{2}$.

Las condiciones que debe cumplir esa estructura lingüística de $E_{1}$ para que sea (discursivamente) apta como razonamiento vienen dadas por el tipo de encadenamiento argumentativo que las vincule. Para Anscombre y Ducrot, lo mismo que para el Nietzsche de la retórica, el sentido de la unidad lingüística no depende de propiedades denotadas por ella en un mundo situado de manera ingenuamente realista en el exterior. La unidad lingüística tampoco depende de pensamientos, sino de los discursos que quepa asociar a tal unidad pues es en virtud de ellos como se da un determinado encadenamiento argumentativo.

Consiguientemente, estos puntos de vista amplían la definición anteriormente planteada porque presentan la argumentación como problema situacional al sostener la existencia de situaciones argumentativas y campos argumentativos per se. Parece pues claro que uno de los conceptos más importantes para mostrar que en los procesos argumentativos se dan, a la par, procesos interpretativos (sin que, hasta ahora, estemos indicando que ambos sean subsumibles el uno bajo el otro sino, antes bien, complementarios) es el concepto de coherencia. En relación al ámbito de problemas propio de las teorias de la argumentación, la importancia del concepto de coherencia en la interpretación del discurso la han puesto de relieve G. Brown y G. Yule (1993).

En las propuestas de Brown y Yule se ha prestado más atención a esa otra cara del problema de la argumentación que aquí entendemos como el problema de la interpretación. Dentro de esta última, lejos de analizarse la naturaleza de los argumentos en sí mismos, se concede mayor atención al análisis de las situaciones argumentativas en 
que aquéllos se producen, así como a la interpretación y valoración de la fuerza argumentativa, los operadores y conectores argumentativos, los topoi implícitos, etc. Propio de este enfoque son sus conclusiones acerca de la presunción de coherencia en el proceso de interpretación del significado. La dilucidación de ese grado de coherencia exige el análisis de varios aspectos, a saber, el cálculo de la función comunicativa que incluye no sólo una comprensión del significado de los enunciados, sino de estos últimos a la luz de su significado en tanto acciones, así como el empleo de conocimientos previos y la producción de inferencias.

Una de las aportaciones más valiosas en torno a la compresión de los enunciados como acciones es la de Labov. Según la perspectiva sociolingüística, habria claramente reglas de interpretación que se usarian para establecer una inferencia no sólo a partir de lo que se dice sino de esto último a la luz de lo que se hace pues las acciones se actualizarian mediante enunciados. Si lo pensamos, caeremos rápidamente en la cuenta de que la mayoría de nuestros intercambios comunicativos son coherentes únicamente presuponiendo esta hipótesis por lo demás fuertemente compartida, a saber, que la estructura de la interacción lingüística no queda fragmentada ni disuelta por el hecho de que los enunciados sean inconexos, pues la continuidad discursiva es ya un motivo para suponer una conexión lógico-discursiva. En este sentido, puede decirse que uno de los problemas fundamentales para toda teoría de la argumentación es el de la inferencia pues es a través de procesos inferenciales como se otorga validez a un supuesto $y$, en general, a una argumentación.

A este respecto, la teoría de la relevancia ${ }^{3}$ sostiene que los cuantiosos procesos inferenciales son consecuencia de que la comunicación tiene una dimensión ostensiva, es decir, es un medio para la manifestación de algo. Y la intención por la que se busca hacer manifiesto algo hace de la inferencia un proceso coadyutor de aquel otro. La teoría de la relevancia de Sperber y Wilson versa precisamente sobre el problema de los supuestos a la luz de los procesos inferenciales, pues dependiendo del grado de fuerza de un supuesto y/o varios supuestos éstos, por lo general, producen inferencias más o menos adecuadas. Se parte también aquí del hecho de que los razonamientos heurísticos no son enteramente falsables o comprobables y que, no obstante, es este tipo de razonamiento el que se utiliza para llegar a construir una hipótesis con la que vislumbrar, de la manera más productiva y atinada posible, las intenciones comunicativas del emisor. La noción de relevancia hace alusión, en definitiva, a la producción de efectos contextuales.

La generación de efectos contextuales relevantes guarda una estrecha relación con el razonamiento inductivo en su modalidad abductiva. En ella, inducción e interpretación ofrecen aspectos tan propios de cada una como indistintos y comunes a ambas. Hay que considerar el problema de la relevancia junto al de implicaturas fuertes e implicaturas débiles: dos de los aspectos más sugestivos de la teoría de la relevancia de Sperber y Wilson. En definitiva, una teoría que surge en oposición al modelo del código basado en la idea de que "un emisor, de acuerdo con un determinado código, emite una seña cuyo referente es ajeno al proceso de comunicación (es un suceso, un estado de ánimo, una verdad científica, etc.). Las señales emitidas viajan a través de un canal y llegan al receptor quien, si posee la clave oportuna, realizará la descodificación" (Tusón, 1984, p. 28$)^{4}$.

En su estudio introductorio a los escritos sobre retórica nietzscheanos Santiago Guervós escribía: "Ya que la epistemología opera -lo mismo que la filosofía- por medio del lenguaje, y el lenguaje es esencialmente retórico, es decir, persuasión, todas las cuestiones que se refieren al lenguaje y a la filosofía son cuestiones retóricas" (Santiago Guervós, 2000, p. 22). Pues bien, parafraseando a Guervós en su ejemplar estudio introductorio, aquí se sostiene que ya que la epistemología opera por medio del razonamiento, y el lenguaje es esencialmente razonamiento, es decir, expresión persuasiva, todas las cuestiones que se refieren a la filosofía y a la epistemología son cuestiones retóricas, dialécticas y argumentativas ${ }^{5}$.

Sin embargo, este enfoque sería insuficiente en sí mismo, pues presenta problemas difícilmente abordables sin asumir la perspectiva propia de una ontología lingüística ${ }^{6}$ donde se pone definitivamente de relieve que el lenguaje no es un instrumento de representación sino que preforma nuestro horizonte de comprensión al estar condicionado por nuestra experiencia del mundo; de modo que es la dimensión especulativa que dota de vida al lenguaje lo que le inclina a la producción incesante de enunciados con función suasoria y disuasoria. 


\section{Valor y estructura de los argumentos}

Las investigaciones de Perelman y Olbrechts-Tyteca (1989) sobre la nueva retórica fueron clasificadas por ellos mismos dentro de la disciplina de la lógica. En cierto modo, puede dividirse la investigación de estos autores en torno a dos problemas fundamentales, a saber: por una parte,

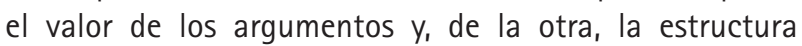
de los mismos. La segunda de las cuestiones hunde sus raíces en la tradición analítica de la filosofía, y conduce a un examen detenido y minucioso de las técnicas de la argumentación.

En el contexto de la filosofía continental, el análisis de las clases de argumentación y de su estructura también ha sido contemplado desde el punto de vista de la tradición de la filosofía trascendental, dando como resultado líneas de investigación como la de $\mathrm{Apel}^{7}$ que puede describirse como una reconstrucción trascendental de las condiciones lingüístico-pragmáticas de posibilidad y validez implícitas en toda argumentación (Apel, 1984).

Sin embargo, en esta aplicación del giro lingüístico a la tradición de la filosofía trascendental existe una contradicción inmanente: concebir la tradición retórica y las teorias de la argumentación a la luz del problema kantiano de una fundamentación última del conocimiento objetivo a partir de la filosofía de la conciencia.

La contradicción radica en que la figura de la conciencia ha perdido definitivamente su carácter de instancia garante del conocimiento objetivo precisamente en este ámbito de problemas, debido a que las condiciones de validez de la argumentación remiten a marcos intersubjetivos elementales, cuya condición de garantes de la validez objetiva de cualesquiera conocimientos obtenidos depende de procesos argumentativos públicos en los que ni la estructura de los argumentos, ni su valor (epistémico, moral, jurídico, estético, etc.) podrian concebirse desde los lineamientos metafísicos de la filosofía trascendental kantiana toda vez que la convicción racional (otrora objetivamente suficiente) y la persuasión (otrora radicada en la índole particular de un sujeto $y$, por tanto, objetivamente insuficiente) pasan a ser analizadas como dos fenómenos interdependientes a partir de la rehabilitación de Aristóteles y Platón llevada a cabo en los años cincuenta ${ }^{8}$ por la nueva retórica y el empuje de las teorías de la argumentación.

Lo que sostenemos puede observarse, por ejemplo, en la defensa llevada a cabo desde la nueva retórica del llamado principio de inercia que postula que no puede rechazarse sin motivo racional algo que se ha aceptado anteriormente. De alguna manera, puede decirse que el principio de inercia es una defensa del importante lugar que ocupa la tópica en los procesos argumentativos ya que sin presuponer algo no puede comenzar a argumentarse. La defensa gadameriana de la idea de prejuicio descansa sobre idéntica razón.

Pero volvamos al tema anteriormente referido, a fin de comprender por qué el anterior ejemplo da idea del fracaso de una aplicación en clave trascendental de los rendimientos lógico-pragmáticos del giro lingüístico.

Que los acuerdos intersubjetivos basados en una idea cuasi-trascendental de la lógica de los argumentos puedan dar lugar a una idea de acuerdo garantizada por una impugnable normatividad que imprimiría la estructura de la argumentación sobre los procesos controversiales o polémicos, es, en definitiva, algo con lo que disintió rotundamente Gadamer, al expresar que no puede haber criterios universales con los que dirimir la validez de los argumentos. Tanto los argumentos como las interpretaciones están históricamente situados. No puede garantizarse racionalmente la generalización de la validez universal de una norma por el hecho de que, en un auditorio universal, todos puedan estar de acuerdo con ella.

La defensa gadameriana del concepto de universalidad queda circunscrita, como ya vimos, a la universalidad de un medio, el medio lingüístico. En éste se observa que rige el principio de la dimensión especulativa del lenguaje que aquí hemos consignado bajo la famosa fórmula gadameriana que reza: "el ser que puede ser comprendido es lenguaje".

Mas de la condición del medio lingüistico no puede derivarse la validez universal de ninguna regla o norma emanada del asentimiento general, incluso aunque éste fuese concebido -hipotética $y$, sin embargo, definitivamentecomo fruto de la validez universal del contenido de la norma. 
Por esta razón, cabe decir que los prejuicios o el principio de inercia modulan y orientan los procesos argumentativos, conduciéndoles hacia formas de consenso en las que la modalidad de validez ya no puede ser establecida en relación a la universalidad del contenido semántico expresado en la proposición, sino a partir de criterios acerca del valor de los argumentos. Criterios que no sortean el carácter contingente ${ }^{9}$ de los mismos, es decir, su dimensión interpretativa, con la que aumentan, de hecho, la cantidad de principios de inercia de que dispone una época para reflexionar sobre otros argumentos en general, siendo una de las tareas más importantes la de distinguir entre los razonamientos erísticos (basados en premisas aparentemente aceptadas) y los razonamientos en los que sí existe, al menos, una dimensión dialéctica (basados en premisas aceptadas y con los que se exploran posibles contradicciones).

Que el grado de contingencia que atribuye implícitamente Gadamer a la validez de toda argumentación es mayor que la estimada, por ejemplo, por Apel, se hace patente si atendemos a su concepción filosófica de la hermenéutica. Me refiero a que no parece conceder a las premisas de argumentación que conciernen a lo real (divididas por Perelman en hechos y verdades, en contraposición a las premisas de argumentación que son presunciones) el que puedan alcanzar una validez universal frente a un auditorio hipotéticamente universal. Gadamer no concedería esto porque no concibe la validez argumentativa de las premisas de argumentación separadas de los topoi y los principios característicos de la ontología lingüística.

Por todo ello, en relación al problema de la estructura y validez de los argumentos, sostengo aquí que la filosofía hermenéutica vuelve a proponer implícitamente una noción de argumentación en la que las proposiciones que aparecen en los argumentos no pueden disociarse de la estructura de éstos porque, según fue consignado en la tradición de la hermenéutica clásica: pertenecen al todo del texto 0 , tal y como fue expresado por la metáfora organicista de Toulmin $(1958,29)$, van más allá de la suma de sus partes.

Ese todo se conforma lingüisticamente, esto es, en un medio universal, pero no puede proporcionar una condición universal de validez merced a instancias trascendentales reformuladas dentro de un paradigma lógico-lingüistico, sobre todo si aceptamos que todas las proposiciones pueden concebirse como acciones, y que no pueden sustraerse de los contextos pragmáticos en que se profieren $y_{1}$ en virtud de los cuales, significan y connotan. De ahí que Gadamer (1984, p. 656), frecuentemente, entienda que la hermenéutica filosófica se caracteriza por dar pábulo a la disolución de la moderna dicotomía entre filosofía y retórica o nueva retórica dentro de la que él situaría los desarrollos propios de las teorías de la argumentación.

Las connotaciones de una expresión no enturbian, pues, su comprensibilidad (ya que ellas no designan univocamente a su referencia), sino que la incrementan en cuanto que todo el nexo al que se refieren se vuelve en su conjunto más comprensible. Es el todo lo que se construye aquí con palabras [argumentaciones, interpretaciones, etc.] ${ }^{10}$, y que sólo está dado en ellas.

Gadamer mantiene una perspectiva platónica cuando sostiene que la dialéctica es un medio más indicado que la retórica debido a que ofrece la posibilidad de contraargumentar.

El modelo dialéctico de contraargumentación no puede equipararse al retórico si concebimos a este último como medio para mostrar que la pericia del orador puede orientar su posición tanto hacia la defensa como hacia al ataque de lo ya mantenido cuando es el caso que se sostiene un concepto de argumentación en el que ésta no tiene una función específica y, por tanto, se puede usar para defender una variedad tendencialmente ilimitada de perspectivas teóricas o incluso para una variedad no menos limitada de propósitos y fines para la acción.

No es este el caso del modelo argumentativo que prevalece en los procesos interpretativos basado en el método dialéctico del preguntar, en el que la dialéctica es presentada como un medio para la resolución y exposición pragmática y especulativa de tesis enfrentadas ${ }^{11}$. Este método es probatorio, es decir, no es demostrativo; tampoco es un modelo equiparable a los procesos persuasivos en cuanto tales pues su finalidad no es propiamente la persuasión, y sólo se puede aplicar -según Aristóteles- a aquellos asuntos filosóficos cuya notoriedad se pretende mostrar ${ }^{12}$.

A partir de estas primeras distinciones entre dialéctica, retórica y tópica cabe sostener que la hermenéutica filo- 
sófica, si bien no analiza los conceptos de validez y estructura de los argumentos -aunque sí se ocupó de la validez y estructura de las interpretaciones en el período clásico-, proporciona el modelo de una ontología lingüística en el que se sustentan las teorías de la argumentación.

Tanto si mantenemos una perspectiva prescripcionista, descripcionista como instrumentalista para dilucidar si cabe una teoría normativa de la argumentación, es decir, si puede pensarse, y en qué términos, la legitimidad de las normas que regulan la acción de argumentar (respecto a la estructura de los argumentos y al valor argumentativo de los razonamientos), puede decirse que existe una cuestión previa a ésta, a saber: la cuestión de la ontología lingüistica tras el giro lingüistico.

Por ejemplo, se puede sostener que el contenido semántico del concepto normatividad argumentativa es fruto de convenciones 0 , por el contrario que no es, sensu stricto, producto de convenciones. Pero si aceptamos los presupuestos de una ontología lingüística, cabe pensar aún una posición limítrofe. Dado que el concepto de normatividad argumentativa remite al más general de valor argumentativo, las hipotéticas convenciones en las que habría de basarse la norma o las reglas con las que argumentar -según la posición convencional- llegarían a ser dirimibles mas llegado un punto no son negociables, porque su valor argumentativo estaría estrechamente vinculado a la condición epistémica de ser un acto de mostrar un argumento mediante una o varias proposiciones.

La convención de la norma -incluso si se sostiene una concepción convencional sobre el fundamento de las leyes lógicas-, al formar parte de la actividad argumentativa, acabaría adquiriendo una dimensión normativa.

Pues bien, en virtud de una exploración de índole no tanto reproductiva cuanto "propositiva" con la que actualizar el pensamiento gadameriano, sostenemos aquí que la ontología lingüística es el modelo implícito en los desarrollos de la teoría de la argumentación por dos razones: la primera, porque es en el lenguaje donde se efectúa la acción de argumentar. $Y$ la segunda, porque es en virtud del lenguaje como se realiza una compleja consignación del lógos histórico. Fórmula que, en el pensamiento de Gadamer, aúna tanto el concepto griego de racionalidad de la naturaleza, como el hegeliano de razón en la historia no siendo, al cabo, ni únicamente esto último ni tampoco lo primero. Pues la formulación general del lógos histórico se expresa en principios.

Consiguientemente, por ser una modalidad de racionalidad inconcebible más allá de la(s) línea(s) histórica(s) del tiempo, no proporciona modelos de normatividad de una necesidad tal como para autoerigirse ni en un instante del tiempo histórico ni, en puridad, tampoco en el concepto de un espíritu absoluto hegeliano, sino acaso en modelos cuya normatividad depende del (ser) del lenguaje como forma de mediación entre:

(1) la conciencia común de una época,

(2) el desarrollo del razonamiento característico de lo que Gadamer llama la conciencia social (por lo que en toda época habria una modalidad de virtud retórica compartida o, al menos, una lógica, una retórica civil, así como una psicología y una sociología del razonamiento),

(3) la experiencia de lo verosímil,

(4) la experiencia del valor normativo (lógico, ético y jurídico) de las interpretaciones del mundo -entendiendo "mundo" no sólo en el sentido de cosmovisión, sino como conjunto de códigos, teorias, tradiciones, etc. que constituyen un saber-, las cuales podrian llegar a motivar e incluso, en algunos casos, conformar o preformar valores argumentativos.

La definición de argumentación e interpretación presenta límites semánticos de una porosidad tan sutil como elocuente, habida cuenta de que, en última instancia, toda forma de conocimiento no puede por menos que plantear y construir su objeto o su tópica mediante procesos argumentativos e interpretativos. En ello radica que estos últimos puedan caracterizarse como la nueva koiné de nuestro tiempo.

\section{LAS RAíces heRMENÉUticAS deL CAMPO ARGUMENTAL}

En el Epílogo escrito en 1972 a la tercera edición de Verdad y método, Gadamer comenzaba rememorando que ya 
incluso cuando en 1959 puso fin a su libro dudaba de que no hubiese llegado demasiado tarde $y$, en consecuencia, pudiese resultar superflua una investigación realizada desde una perspectiva como la suya, que partía de la tradición humanista romántica de las ciencias del espíritu si bien no reconocía en dicha tradición ni su límite ni su objetivo. Pero ¿en relación a qué llegaba demasiado tarde? ${ }^{13}$.

Gadamer tenía a la vista "los signos que anunciaban una nueva ola de hostilidad tecnológica contra la historia" (Gadamer, 1984, p. 640). A juicio del filósofo alemán éstos se multiplicaban a consecuencia de la recepción de la teoría de la ciencia y de la filosofía analítica anglosajona. Le parecía a él notoria su influencia sobre las nuevas perspectivas en las ciencias sociales y la socio-lingüistica, sobre el auge de la metodología estadistica aplicada, la organización tecnológica de la investigación y, en fin, causa manifiesta de las muchas consecuencias derivadas de la asimilación de "planteamientos anglosajones" (Gadamer, 1984, p. 641).

Un punto de vista nada halagüeño -se nos dirá- si lo que se busca es justificar la proximidad entre la hermenéutica filosófica gadameriana y los desarrollos propios de las teorías de la argumentación; ámbito que aunque no sea exclusivo de la filosofía escrita en lengua inglesa, si debe mucho al fenómeno que Rorty describió como la crisis de la filosofía analítica y el auge de la postanalítica (Rorty, 1982, p. 225). Incluso puede decirse que, salvando las distancias, la interpretación de la historia de la filosofía según la cual existiría una tradición continental y una anglosajona o anglófona, tiene mucho que ver con la escasez de estudios en torno a la asunción de puntos de vista similares, no equidistantes, y en los que las problemáticas fueran consignadas de manera tal que unas perspectivas enriquecieran otras: las continentales a las analíticas, y viceversa. Tal es el caso de, por una parte, la hermenéutica filosófica, de raigambre claramente continental, y las teorías de la argumentación que comparten al menos una veta claramente postanalítica y anglosajona.

Junto a Kuhn ${ }^{14}$ y a Apel, el caso de Tugendhat es claramente paradigmático, pues dentro de la tradición hermenéutica en la que se formó -más precisamente, bajo la influencia de Heidegger- ha realizado uno de los intentos más sugestivos por mostrar el interés e incluso la necesidad de adentrarse en la "filosofía lingüistica anglosajona" (una filosofía centrada en el problema del lenguaje, la lógica, la argumentación, etc.), para desarrollar plenamente el legado de la filosofía continental, siendo a su juicio Frege una referencia primordial dentro de ese hipotético proyecto de integración de analíticos y continentales que ha generado ríos de tinta ${ }^{15}$.

La perspectiva hermenéutica llegaba demasiado tarde en relación a la influencia de la idea de rigor metodológico de la ciencia moderna, y Gadamer parecía querer adelantarse a la recepción de su propuesta cuando, de seguido, escribía que "lo que da vigencia a la hermenéutica es algo muy distinto y que no plantea la menor tensión con el ethos más estricto de la ciencia" (Gadamer, 1984, p. 641).

Gadamer sostiene que la investigación que propone no sólo "procede de la praxis concreta de la ciencia" (ibidem, p.642), sino que incluso ofrece una aportación que media entre la filosofía y las ciencias. $Y$ al parecer, ni una cosa ni la otra podian llevarse a cabo sin "ir más allá del reducido horizonte de interés de la metodología de la teoría de la ciencia" (ibidem, p. 642), por ello, puede decirse que la hermenéutica impulsa la perspectiva filosófica que critica y va más allá del factum de la ciencia del neokantismo y del positivismo.

[...] la hermenéutica es relevante igualmente para la teoria de la ciencia en cuanto que, con su reflexión, descubre también dentro de la ciencia condiciones de verdad que no están en la lógica de la investigación sino que la preceden. Esto ocurre en particular, aunque no sólo, en las llamadas ciencias del espíritu, cuyo término inglés equivalente, moral sciences, muestra que estas ciencias tienen por objeto algo de lo que forma parte necesariamente el mismo sujeto que conoce.

Gadamer busca hacer evidente aquí que la construcción del ideal de ciencia, así como la hipótesis de un objeto de investigación científica son cuestiones tan determinantes como para llevarle a poner en duda que acaso su aportación llegue demasiado tarde y que, por tanto, no haya llegado aún el momento de reconsiderar el objeto, el método y el estilo propios de la investigación hermenéutica, ciertamente presente en las moral sciences o ciencias del espiritu, mas no sólo en ellas. A mi juicio, Gadamer formulaba aqui estratégicamente sus dudas con el fin de abrir o incluso producir, una vez más, el contexto de reflexión que 
le permitiría volver a plantear la problemática e incluso ilustrarla de modo tal que fuera también provechosa, de manera retrospectiva al menos, para la tradición positivista y la neokantiana. La propuesta de Gadamer es esencialmente controversial, él mismo lo reconoce cuando afirma que "la agudización de la tensión entre verdad y método en mi [...] trabajo estaba guiada por una intención polémica" (ibidem, p. 646).

En la medida en que su trabajo representa también la apertura a un legado filosófico como la hermenéutica clásica y la hermenéutica de la facticidad heideggeriana inconcebibles, ya desde el comienzo, sin su determinante actualización (la hermenéutica filosófica, la ontología lingüística), puede decirse que en su trabajo tiene a la vista las perspectivas de otros colegas -europeos todos ellos-, cuya labor crítica está tan relacionada con la recepción de su obra como con una forma otra de entender la actualización del legado hermenéutico en su conjunto. A tal punto es solamente retórica la duda que le asalta sobre si su aportación llega "demasiado tarde", toda vez que parece consciente de la influencia de su perspectiva sobre los debates filosóficos desarrollados, por ejemplo, por Betti, Apel, Habermas, Vattimo, Rorty, Ricoeur, etc. Pero también tuvo noticia y siguió muy de cerca las controversias desarrolladas en los ámbitos que él describía como "terrenos especiales de la metodología hermenéutica", a saber: la hermenéutica jurídica, la teoría de la literatura, la hermenéutica teológica y la hermenéutica en las ciencias sociales.

Como es sabido, la filosofía gadameriana conceptualiza criticamente un prejuicio epocal acerca del supuesto alcance y determinación ontológicas del método científico que degrada la praxis por pervertir el asunto primordial de la racionalidad constituida políticamente en la que él indaga a través del concepto aristotélico de phrónesis, así como del principio de la conciencia histórica. Gadamer fue siempre consciente de que el legado aristotélico implicaba atender a este principio prudencial o principio activo de experiencia en el seno de la política, para poder entender el alcance y los límites de toda otra forma de determinación posterior de lo general a través, por ejemplo, de inducciones. En El significado paradigmático de la hermenéutica jurídica indicaba que el juicio determinante kantiano (con el que se subsume lo particular o singular bajo una forma de generalidad dada), pero también el juicio reflexionante o de discernimiento (que da con conceptos para describir o subsumir cualesquiera formas de singularidad) responden, en verdad, a una forma de escisión harto artificiosa: pues lo general siempre tiene su límite en lo singular originario.

Frente a este modelo, Gadamer ensaya otros procedimientos con los que ejercer la actividad filosófica. Ya hemos visto que una de esas formas consistió en concebir la historia conceptual como una metodología propiamente filosófica; ella va más allá de la semántica o teoría del significado -de los acontecimientos históricos- con objeto de indagar en la constelación histórica desde la que algo puede llegar a significar algo, producir algo, actualizar algo e incluso pronosticar algo. Pero por encima de todas esas formas de discursividad está el pensamiento de una ontología hermenéutica u ontología lingüistica que da una idea del paralelismo existente entre el giro lingüistico y el hermenéutico.

Existe una profunda conexión entre la ontología lingüistica y los presupuestos filosóficos presentes en los desarrollos de la argumentación: la proximidad histórica entre ambos movimientos es una de las razones que explican el efecto de esa nueva koiné de la que, con frecuencia, se olvida que representó también una crisis y, a su vez, una nueva koiné para la filosofía postanalítica. Pese a la falta de distancia temporal, Gadamer (1994, p. 661) parecía ser consciente de ello cuando afirmaba:

Echo de menos un mayor reconocimiento del hecho de que éste es el ámbito que la hermenéutica comparte con la retórica: el ámbito de los argumentos convincentes (no de los lógicamente concluyentes). Es el ámbito de la praxis y en general de la humanidad, cuya tarea no aparece alli donde es vigente el poder del "férreo concluir", al que hay que someterse sin discusión, ni tampoco alli donde la reflexión emancipadora está segura de su "acuerdo contrafáctico", sino alli donde determinados puntos discutibles deben llegar a dirimirse mediante una reflexión racional. [Es] el arte de hablar y argumentar (y de su otra cara silenciosa, la reflexiva deliberación consigo mismo) [...] El que el arte de hablar se dirija también a los afectos, como se viene comprendiendo desde la antigüedad, no quiere decir en ningún caso que con ello quede fuera de lo razonable.

El tema de la retórica es recurrente en la obra de Gadamer (Beuchot, 1991) y, por ello, es uno los tópicos más importantes en la historia de su recepción ${ }^{16}$. Aqui se sostiene que 
el problema de la argumentación era igualmente de una importancia extrema, mas Gadamer lo concibió implícito en el problema de la retórica y la dialéctica, así como en el de la inducción y la applicatio.

El propio Gadamer, que no gustaba en exceso de enriquecer sus textos con excesivas notas a pie de página, dedica sin embargo una a elogiar la importancia de los trabajos de Perelman, en ella escribía: "Los trabajos de Chaim Perelman y sus discípulos me parecen una aportación valiosa a la hermenéutica filosófica, sobre todo su Traité de l'argumentation, en común con L. Olbrecht-Tyteca, y recientemente Le champ de l'argumentation" (Gadamer, 1984, p. 661).

Mas, aunque era de la opinión de que el concepto de reflexión emancipadora era "demasiado vago e indeterminado" como para explicar la complejidad de la reflexión racional o la dimensión práctica y política de los razonamientos como ideal para alcanzar una ilustración total, no se demoró en análisis detallados sobre ese arte del hablary del argumentar (verdadera sabia de los procesos interpretativos), acaso subsumible dentro de un ars interpretandi con el que dirimir y calcular al menos parcialmente los asuntos más controvertidos y complejos, para los que no existen argumentos más convincentes que aquellos que no son producto del férreo concluir.

\section{UN MÉTODO SIN OBJETIVIDAD}

Dediquemos unas líneas a justificar el ámbito y definición de los sentidos de hermenéutica a fin de clasificar, dentro de la tradición hermenéutica, nuestra propia propuesta.

Si bien se suele despachar con presteza el origen etimológico del término, no es menos cierto que la definición de esta voz como "expresión" (de un pensamiento), con frecuencia, encubre la variedad de sentidos y diferencias atribuibles al ars interpretandi.

Según puso de relieve la investigación de Betti (1995), puede decirse que existe una hermenéutica intransitiva cuya finalidad es el entender en sí mismo; una hermenéutica transitiva o reproductiva cuya finalidad es volver algo transmisible, hacer entender; y una hermenéutica normativa o dogmática cuya finalidad es reglar el obrar. Aunque habria que añadir que toda hermenéutica dogmática o normativa es reproductiva, comprensiva, de otro modo no podria ser aplicativa.

Este esquema está presente en las definiciones de las distintas perspectivas de la hermenéutica esbozadas por Richard E. Palmer (1969, pp. 53-67) que van desde la hermenéutica entendida como exégesis bíblica (transitiva), hasta la hermenéutica entendida como metodología lingüística (transitiva), como ciencia de la comprensión lingüística o hermenéutica general (intransitiva), la hermenéutica entendida en tanto metodología de las ciencias del espíritu (intransitiva), la hermenéutica como fenomenología o indagación en la preestructura ontológica del Dasein (intransitiva) y, finalmente, la hermenéutica como interpretación simbólica (transitiva).

A su vez, es preciso comprender dicho esquema como una respuesta al problema de definir, mediante aplicaciones hermenéuticas funcionales, qué entendemos por racionalidad. Así pues, el esquema de la tradición hermenéutica no se refiere a otra cosa que al problema de dar razón o fundamento de los problemas epistémicos: ¿por qué se acepta algo?, ¿por qué se supone algo?, ¿por qué se sabe algo o se concluye algo $y$, en definitiva por qué se interpreta algo como algo? y los problemas normativos, en los que podrian incluirse también los intencionales: ¿por qué debe hacerse algo?, ¿por qué debe aplicarse un norma? ¿por qué hice algo o reproduje así algo?

Dicho esquema se ha desarrollado en tres grandes corrientes en las que se adopta bien una perspectiva ontológica bien metodológica, bien crítica. Ahora bien, es la concepción de la hermenéutica intransitiva (la referida al problema del comprender, del interpretar en sí mismo) aquella que ha despertado más interés en el panorama filosófico contemporáneo. Como ya se ha sugerido anteriormente, la distinción entre una perspectiva intransitiva, una transitiva y una normativa tiene una utilidad clasificatoria inmediata, general, pero no es rigurosa, puesto que no se puede abarcar el problema del comprender o interpretar sin, al instante, estar al cabo indagando en aquello que se hace transmisible por medio de ese comprender o ese interpretar. La clasificación en hermenéutica cognoscitiva, reproductiva y normativa reproduce el mismo esquema presente incluso en la distinción entre la subtilitas implicandi, la subtilitas explicandi y la subtilitas applicandi. 
Precisamente, en virtud de una sutil distinción conviene no hacer distingos demasiado severos entre el enfoque transitivo y el intransitivo. La hipótesis que aquí desarrollamos se suma a otros planteamientos existentes acerca de la proximidad de la filosofía continental y la anglosajona ${ }^{17}$ (en su derivación postanalítica) y plantea la hipótesis de que no hay investigación hermenéutica de naturaleza intransitiva que no haya de abordar el problema de la interpretación desde el punto de vista de los procesos interpretativos. Dentro de ellos, los argumentativos son tan importantes como para no poder distinguir entre la transitividad y la intransitividad, si asumimos una perspectiva flexible en torno a la argumentación. Así, las famosas y abundantes afirmaciones gadamerianas acerca de la radical diferencia entre el problema de la hermenéutica asumido desde una perspectiva intransitiva (o filosófica) y una transitiva (referida a los problemas metodológicos de los que depende la eficacia de la reproducción o transmisión de algo, una composición musical, por ejemplo) resulta tan sutil como vacua más allá de los propósitos investigativos de su obra, de su contexto filosófico y de su proyecto de rehabilitación del legado filosófico.

Esta perspectiva se alejaría de la férrea tesis gadameriana según la cual cuando se comprende no se comprende mejor "ni en el sentido objetivo de saber más en virtud de conceptos claros, ni en el de la superioridad básica que posee lo consciente respecto a lo inconsciente de la producción; bastaría decir que cuando se comprende, se comprende de un modo diferente" (Gadamer, 1984, p. 336). El posicionamiento gadameriano frente al proyecto del jurista italiano consistente en alumbrar una forma de sintesis entre objetividad y corrección interpretativas e indagación psicológica acerca de la intentio autoris, parece claro y sumamente persuasivo: la tradición orienta nuestra comprensión invalidando el concepto de objetividad tal y como lo entiende Betti, en cuya formación jugó un papel determinante el realismo fenomenológico de N. Hartmann y el idealismo trascendental. El planteamiento gadameriano se sustenta en la idea de principio como instancia regulativa en el plano de la constitución de nuestro conocimiento que, precisamente, porque preforma nuestra comprensión no garantiza la objetividad de la producción misma de conocimiento. Gadamer elabora, según mi punto de vista, una ontología lingüística como filosofía acerca de principios comunes, esto es, principios que todo sujeto que elabora alguna forma de comprensión reconoce como generales o comunes, mas entendiéndolos también como principios lógicos porque, tanto si el sujeto cognoscente es consciente de su principialidad como si obran en su comprensión o conocimiento de algo, subyacen a todo discurso racional.

Mas un discurso racional no lo es en la medida en que se nos represente como objetivo, habida cuenta de que la objetividad no es una virtud epistémica si asumimos, por ejemplo, que el principio de la historicidad de la comprensión o el principio de la dimensión especulativa del lenguaje rigen en cualquier forma de comprensión expresada en un medio lingüistico. Por el contrario, un discurso racional puede estar fundado en razonamientos no deductivos, incluso no objetivos, y aun así, se nos puede presentar como concluyente; este modelo de razonamiento, el de las moral sciences, era el que fascinaba a Gadamer. Él asociaba dicho modelo de razonamiento al medio lingüístico, a la comunicación dialogada, a la indagación dialéctica en sentido platónico y a la productividad de efectos de verdad con la cual participamos en el juego retórico. A mi juicio, en esto se basa la veta metódica en la hermenéutica: una ontología lingüística es, a su vez, un medio y un método de investigación para una teoría acerca de las modalidades de la argumentación.

Luis Martínez de Velasco $(2003$, p. 55) se refería, de alguna manera, a la misma idea cuando escribía que "en su más íntima esencia, el pensar filosófico desemboca en la argumentación hermenéutica. Sin embargo, históricamente, vino a registrarse en su interior un determinado "endurecimiento semántico" que abrió las puertas a la ilusión del método".

Por su parte, Mauricio Ferraris $(2000$, p. 282) sostiene que la perspectiva heideggeriana sobre la determinación ontológica del comprender transforma por completo el problema de la relación entre hermenéutica y epistemología (una relación conflictiva, amplia, que atraviesa la historia misma de la filosofía contemporánea, consignada de modos muy diversos, desde distintos ámbitos y tradiciones filosóficas, durante la historia de la indagación en torno a la legitimidad epistemológica y ontológica de las ciencias del espíritu ${ }^{18}$. Según el autor, una de las razones que justificaría la constante tensión entre hermenéutica y epistemología radica en el hecho de que durante la modernidad filosófica, la tradición bajo la que se plantearon la mayor 
parte de los problemas filosóficos no fue la humanista ni la ontológica propiamente, sino la epistemología "en sus articulaciones dentro de las ciencias del espiritu" (Ferraris, 2000, p. 283).

Consiguientemente, si acertamos a representarnos la relación entre hermenéutica y epistemología en un sentido amplio, ésta habría de abarcar, especialmente, al paradigma moderno y su influencia sobre la empresa gadameriana -de espíritu postdiltheyano-, de repensar las ciencias del espiritu no ya bajo el problema de la especificidad de las virtualidades epistémicas propias de su método de investigación e interpretación, sino a la luz de una cuestión previa, a saber, la del modelo de una ontología lingüística.

Lo que nos interesa traer aquí a colación es la hipótesis histórica según la cual esta problemática habria sido determinante en relación a la tradición neopositivista presente en la filosofía anglosajona $y$, sobre todo, en el complejo mapa de la filosofía postanalítica. Según Ferraris, la filosofía analítica de los últimos treinta años indaga en torno al problema de la acción (o más específicamente "a la posibilidad de una filosofía analítica de la acción"19).

Así las cosas, el problema de la construcción del concepto de racionalidad, a la luz de los procesos argumentativos, entraría dentro de ese conjunto de problemas filosóficos en los que se observa que el movimiento producido por la dialéctica hermenéutica-epistemología-ontología es de doble sentido o, para decirlo con más propiedad: es el movimiento de un problema que, yendo de una tradición a otra, muestra que camino arriba, camino abajo es uno y el $\mathrm{mismo}^{20}$. Es un camino que une el diálogo interior con el diálogo exterior de los signos y las cosas: un camino de dos sentidos y una misma dirección, pues "ya no se trata de un camino que conduzca a la interioridad, similar a la de la exhortación agustiniana, sino de un camino de completo abandono al exterior, en cuyo recorrido el que se busca a sí mismo termina encontrándose" (Gadamer, 1976, p. 29). Cada intento de salir del lenguaje permanece en el interior del lenguaje, como cada descripción de la misma cosa puede implicar descripciones opuestas (ora el camino se dice hacia arriba, ora hacia abajo). Nos referimos aquí a la circunstancia de que según interpretación de Hipólito -que pudo contar con un manual en el que las sentencias del filósofo de Éfeso aparecían clasificadas por temas- la expresión "el camino arriba y abajo" se tomó como una ilustración de la unidad de los opuestos. Y es en este sentido en el que se expresa aquí la imagen del camino hacia el (diálogo) interior y hacia el (mundo) exterior: ambos son extremos opuestos unidos por la lengua que imprime sobre ellos una forma de interpretabilidad constituyente (de ambos: diálogo y mundo) y análoga (entre el diálogo y el mundo).

Nota: El trabajo de investigación que ha dado como resultado este artículo forma parte del Proyecto de Investigación: "Una nueva filosofía de la historia para una nueva Europa" HUM2005-02006/FISO, así como de la Red Interuniversitaria "Construyendo Europa: tradición, valores y nueva ciudadanía" HUM2004-21961-E del Programa Nacional de Humanidades del Ministerio de Educación y Ciencia (MEC). Este trabajo se ha llevado a cabo gracias a un contrato postdoctoral del Ministerio de Ciencia e Innovación (MICINN) que se desarrolla en el Department of Speech Communication, Argumentation Theory and Rhetoric de la Facultad de Humanidades de la Universidad de Ámsterdam.

\section{NOTAS}

1 Según la teoría de la argumentación de Anscombre y Ducrot un operador argumentativo es un morfema que aplicado a un enunciado (o expresado dentro de un enunciado) modifica de manera relevante la fuerza y el alcance argumentativo del contenido de dicho enunciado. Por ejemplo: no es lo mismo decir "son las cinco de la tarde" que decir "ahora no son más que las cinco de la tarde".

2 Los conectores argumentativos son aquellos morfemas cuya función consiste en enlazar enunciados de manera tal que éstos expresen un argumento como consecuencia del conector. Por ejemplo, en el enunciado "no creo que llegue a estas horas,
Aceptado: 28 de diciembre de 2009 
de manera que me voy a casa", puede decirse que de manera que funciona como un conector entre un argumento y su conclusión.

3 Algunos autores prefieren traducir "relevance" por "pertinencia" el término al que se refieren D. Sperber y D. Wilson (1995).

4 La teoría del modelo de comunicación basado en la codificación y descodificación de un código se debe a C. E. Shannon y W. Weaver (1949).

5 Se puede observar que esta paráfrasis lo es también respecto a la conclusión a la que llegaba Ducrot cuando decía que: "Buscando el papel argumentativo que desempeña la envoltura lingüistica de los hechos, llegamos a no distinguir esa envoltura de los hechos mismos". Cfr. 0. Ducrot; J.-C. Anscombre (1994, p. 194).

6 Entre los autores que se han dedicado a desarrollar la orientación lingüistica de la ontología es, a nuestro parecer, Gadamer quien ha dedicado los esfuerzos más determinantes. Así lo considera también Vattimo (1998, p. 115).

7 Como se sabe, la filosofía de Apel comienza inspirándose en los trabajos de Peirce y defiende un giro semiótico de la filosofía trascendental kantiana. De esta investigación inicial surgieron los problemas relativos a la cuestión de los intereses cognoscitivos en el sentido en que dicha cuestión es abordada por Habermas.

8 Me refiero aquí a los hitos más importantes dentro de la historia de las teorias de la argumentación -con respecto a la cual, si no me equivoco, aún andamos escasos de estudios históricos sistemáticos-, si bien habría que añadir el estudio de Ch. Plantin (2002, pp. 19 y ss.) en el que se puede encontrar una breve sección dedicada a enumerar algunos de las aportaciones más importantes a la teoria de la argumentación que él sitúa igualmente en la década de los cincuenta.

9 Julián Marrades (2006, p. 72) sostiene la hipótesis de que el concepto gadameriano de infinitud de sentido resulta controvertido en el sentido de que si se hace depender de él el sentido de las interpretaciones, entonces, se define implícitamente el malentendido como un fenómeno contingente en el sentido de "un accidente siempre superable en el proceso del entendimiento". Aquí se amplía el ámbito de aplicación del adjetivo "contigente" hasta abarcar las interpretaciones sin más (sean éstas malos entendidos o no), en razón, precisamente, de la noción gadameriana de infinitud de sentido.

10 El contenido del corchete es un añadido mío. Lo mismo que las palabras contienen el todo del sentido de un conjunto de problemas que se busca hacer más comprensible -respecto al cual, las connotaciones sólo representan una nota más a añadir en la busca de su comprensibilidad-asimismo, puede decirse que los argumentos y las interpretaciones tienen ese mismo fin: el aumento de comprensión tanto en el caso de que éstas resulten consistentes, como si no.

11 En este sentido, puede decirse que el modelo pragma-dialéctico de van Eemeren y Grootendorst desarrolla los presupuestos normativos de la dialéctica. Véase uno de sus más relevantes trabajos: A Systematic Theory of Argumentation. Cambridge: Cambridge University Press, 2004.

12 La concepción de Gadamer en torno a la dialéctica disiente de la desarrollada en el estudio clásico de Hamblin sobre las falacias con el que se reavivó en la década de los setenta el campo de la teoría de la argumentación. En efecto, Gadamer no era un entusiasta de las orientaciones formalistas y no concebía que el problema de la dialéctica se pudiera reducir a un estudio formal sin que ello desvirtuase la importancia del alcance político y especulativo del mismo. No obstante, la obra de Hamblin fue determinante para la corriente posterior de lógica formal que exploraron J. Woods y D. Walton (1989).

13 A finales de la década de los sesenta tuvo lugar un amplio debate en torno a la obra de Gadamer, las tesis de más calado las sostuvo Habermas (1988) en Un Informe bibliográfico: la lógica de las ciencias sociales y apenas tres años después en La pretensión de universalidad de la hermenéutica, a dichas críticas Gadamer respondió con dos trabajos que se editaron en la segunda parte de Verdad y Método, a saber: "Retórica, hermenéutica y crítica de la ideología" y un segundo texto en respuesta a la segunda de las críticas habermasianas: "Réplica a Hermenéutica y crítica de la ideología" (Gadamer, 1984, pp. 222-242 y pp. 243-266). Pues bien, el Epílogo debe entenderse también como una respuesta que surgida en el contexto de esta controversia.

14 En su libro The Essential Tension. The University of Chicago Press, Chicago, Kuhn afirmaba que aquellos que, como él, sostenian que el papel jugado por la historia y la hermenéutica era fundamental habria bien en lanzar un puente entre la tradición continental y la anglosajona.

15 Uno de los estudios más competentes a este respecto sigue siendo el de Franca D'Agostini (2000). Franca D'Agostini cita varios estudios de interés a partir de los cuales habría 
que entender su reconstrucción de la historia de la filosofía, a saber: el de I. Hacking (1975) donde sostiene la tesis de que la filosofía analítica es más pobre que la continental, acaso también más inmadura, y no cuenta con figuras como Kant, Hegel o Marx, etc. La perspectiva desarrollada por D. E. Cooper (1994) resulta aquí de especial interés por prestar atención a la modalidad argumentativa: la tradición analítica es rigurosa, minuciosa, sintética, mientras que la continental construye la perspectiva y hace uso de explicaciones históricas, extensas, e interpretativas. Igualmente interesante es el punto de vista de J. Hintikka porque da cuenta del hecho de que numerosos filósofos de tradición analítica reciben claras influencias de la tradición hermenéutica -que Hintikka personaliza en la figura de Heidegger y en su método para volver a pensar las palabras a través de aproximaciones etimológicas, para retornar poéticamente al instante inaugural de significación como donación que va más allá no sólo de la reorientación metafísica del lenguaje filosófico o de su huella semántica, sino incluso de la afamada distinción rortyana entre la filosofía descriptiva y la interpretativa. En lo que respecta a la tradición postanalítica, aquí se busca producir argumentos (en la mayoría de los casos de naturaleza analógica) con los que volver a situar la hermenéutica en el mapa-esquema que F. D'Agostini elaboró hace ya una década, y en el que la hermenéutica aparecía dentro del conjunto de corrientes que conforman la "racionalidad continental" (existencialismo, teoría crítica frankfurtiana, postestructuralismo) frente a la "racionalidad analítica" (pragmatismo, neopositivismo, filo- sofía analítica americana, inglesa, racionalismo crítico). En dicho mapa, la hermenéutica habría de situarse en un lugar intermedio, como elemento de ambos conjuntos, compartiendo dicho espacio con otras corrientes (fenomenologia, estructuralismo, teóricos de los actos de habla, teoría crítica habermasiana, epistemología postpositivista).

16 Precisamente, Vattimo (1988, p. 122) cree interpretar más fielmente a Gadamer que Apel o Habermas cuando entiende la hermenéutica como retórica. Es a través de esta perspectiva como se comprende, por ejemplo, la aplicación de la perspectiva hermenéutica a la filosofía de la ciencia. Sobre la conexión entre hermenéutica, retórica y lenguaje científico, es de gran interés el libro de M. Pera (1991). También Rorty comparte con Vattimo este punto de vista: la hermenéutica tendría que ver con nuestro modo de estar en el mundo $y$, en este sentido, con nuestra necesidad de educación, de formación. Los aspectos normativos y metodológicos de la hermenéutica han sido puestos de manifiesto más rotundamente por Apel y Habermas. El primero, en su intento por hacer confluir la tradición de la filosofía trascendental, la hermenéutica y la analítica. El segundo, con su indagación de las condiciones de validez que permiten realizar una reconstrucción racional de nuestras disputas, comunicaciones, etc.

17 Es ya clásica la alusión del autor de La estructura de las revoluciones científicas al hecho de que era menester salvar la distancia entre la filosofía continental (refiriéndose a la hermenéutica) y la filosofía anglosajona en Kuhn (1982, p. 15).

18 De alguna manera, la propia historia de la hermenéutica da una idea del complejo decurso de esa relación: desde el prejuicio platónico de que el intérprete no puede entregar ni explicar con toda claridad el mensaje que transmite, hasta la metáfora de la naturaleza como un libro abierto que es preciso investigar interpretando sus signos y la distinción de Dilthey (en clave metodológica) entre las ciencias de la naturaleza y las ciencias del espíritu. Sin embargo, en lo que se refiere al decurso del problema filosófico de la interpretación, según la perspectiva de Ferraris, será en la filosofía de Wittgenstein y de Heidegger donde se observa ese giro determinante hacia el horizonte 0 fondo del lenguaje como instancia desde la que volver a replantear el problema del conocimiento, el problema de los juicios sintéticos a priori y el de su posible vinculación con el concepto de categorias prelingüisticas.

19 Cfr. M. Ferraris (2000, p. 27).

20 Según reza la sentencia de Heráclito referida por Hipólito. Cfr., a este efecto, la edición de G. S. Kira; J. E. Raven; M. Schofield (1987, p. 275).

\section{REFERENCIAS BIBLIOGRÁFICAS}

Apel, K-0. (1994): Semiótica filosófica, Buenos Aires, Almagesto.

Aristóteles (1982): Tratados de lógica (Organon), Madrid, Biblioteca Clásica Gredos, vol. 1, Tópicos 100 a 30, 104 a 8.

Betti, E. (1995): Teoria generale della interpretazione, Millano, A. Guffrè.

Beuchot, M. (1991): "Retórica, diálogo y argumentación", en Diálogo filosófico (20): 193-199.

Brown, G; Yule, G (1993): Análisis del discurso, Madrid, Visor Libros. 
Cooper, D. E. (1994): "Analytical and continental philosophy", en Proceedings of the Aristotelian Society (1): 1-18.

Corcoran, J. (1994): "Argumentaciones y lógica", en Agora (13): pp. 27-55. D'Agostini, Franca (2000): Analíticos y continentales. Guía de la filosofía de los últimos treinta años, Madrid, Ediciones Cátedra.

Ducrot, 0.; Anscombre, J.-C. (1994): La argumentación en la lengua, Madrid, Gredos, 1994.

Eemeren, F. y Grootendorst, R. (2004): A Systematic Theory of Argumentation. The Pragma-Dialectical Approach, Cambridge University Press, Cambridge.

Escandell Vidal, V: (1999): Introducción a la pragmática, Barcelona, Ariel.

Ferraris, M. (2000): Historia de la hermenéutica, Madrid, Ediciones Akal.

Gadamer, H.-G. (1976): Vernunft im Zeitalter der Wissenschaft, Frankfurt, Suhrkamp.

Habermas, H. (1998): La lógica de las ciencias sociales, Madrid, Tecnos.

Hacking, I. (1975): Why Does Language Matter to Philosophy?, Cambridge; New York: Cambridge University Press, 1975.

Kira, G. S.; Raven, J. E.; Schofield, M. (1987): Los filósofos presocráticos, Madrid, Gredos.
Kuhn, T. (1982): La tensión esencial. Estudios selectos sobre tradición y el cambio en el ámbito de la ciencia, México, FCE.

Locke, D. (1992): La escritura de la ciencia, Madrid, Ediciones Cátedra.

Marafioti, R. (1997): Temas de argumentación, Buenos Aires, Ed. Biblos.

Marrades, J. (2006): "Experiencia y verdad en la hermenéutica de Gadamer. Algunos problemas", en Muñoz, J.; Faerna, A. M. (2006) (eds.): Caminos de hermenéutica, Madrid, Biblioteca Nueva, pp. 71-95.

Martínez de Velasco, L. (2003): ¿Un nuevo asalto a la razón?, Madrid, Editorial Fundamentos.

Pera, M. (1991): Scienza e retorica, RomaBari, Laterza.

Perelman, Ch.; Olbrechts-Tyteca, L. (1989): Tratado de la argumentación. La nueva retórica, Madrid, Editorial Gredos.

Palmer, R. E. (1969): Hermeneutics: Interpretation Theory in Schleiermacher, Dilthey, Heidegger and Gadamer, Evanston, Northwestern University Press.

Plantin, Ch. (2002): La argumentación, Barcelona, Ariel Practicum.

Rorty, R. (1982): "Philosophy in America today", en Consequences of Pragmatism, Brighton, Harvester Press, 1982.
Russell; P. Norvig (2004): Inteligencia artificial. El enfoque moderno, Madrid, Pearson Prentice May, 2. ${ }^{\text {a ed. }}$

Santiago Guervós, L. E. (2000): Escritos sobre retórica, Madrid, Editorial Trotta, 2000.

Schnädelbach, H. (2000): "Tipos de racionalidad", en Éndoxa (12): 397-422.

Shannon, C. E. y Weaver, W. (1949): The Mathematical Theory of Communication, Illinois University Press.

Sperber, D. y Wilson, D. (1995): Relevance. Comunication and Cognition, 0xford, Basil Blackwell.

Toulmin, S. (2007): Los usos de la argumentación, Barcelona, Península, Cambridge, Cambridge University Press.

Tusón Valls, J. (1984): Lingüística, Barcelona, Editorial Barcanova, 1984.

Vattimo, G. (1998): El fin de la modernidad, Barcelona, Gedisa.

Vega, L. (1993): "Tà Éndoxa: argumentación y plausibilidad", en Éndoxa: Series Filosóficas (1): 5-19.

Walton, D. (1998): Informal Logic. A Handbook for Critical Argumentation, Cambridge, University Press, 1988.

Woods, J.; Walton, D. (1989): Fallacies: Selected Papers (1972-1982), London, College Publications.

Zaccaria, G. (1999): "Trends in Contemporary Hermeneutics and Analytical Philosophy", en Ratio Juris (12): 274-285. 